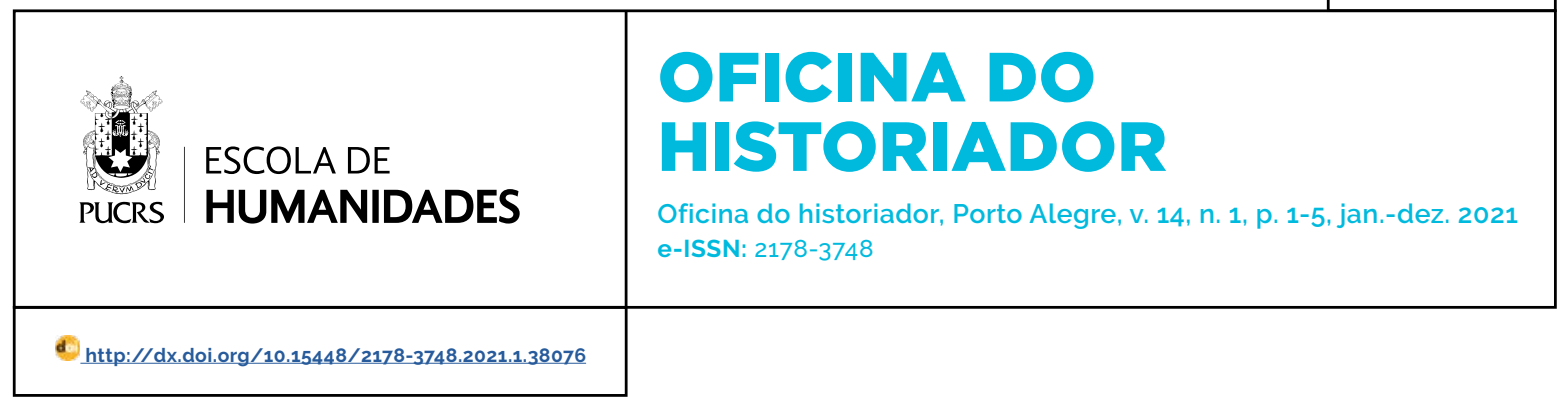

SEÇÃO: RESENHAS

\title{
Abordagens teóricas relacionadas à escrita da história e da literatura
}

\section{Theoretical approaches related to the writing of history and literature}

\author{
Mônica Abramchuk ${ }^{1}$ \\ orcid.org/0000-0002-5539-7522 \\ m.abramchuk@hotmail.com
}

Recebido em: 12/5/2020.

Aprovado em: 19/8/2020.

Publicado em: 12/05/2021.

\section{(c) (1)}

Artigo está licenciado sob forma de uma licença Creative Commons Atribuição 4.0 Internacional.
SOARES, Fabrício Antônio Antunes; SILVA, Ricardo Oliveira da. História e literatura: abordagens interdisciplinares. Criciúma, SC: UNESC, 2019.

O século XIX é fundamental para entender de que maneira a história se consolidou como ciência ${ }^{2}$, pois foi nesse periodo que o historiador passou a ser considerado um cientista, e, como consequência, foi nesse momento que a questão metodológica passou a ser uma preocupação. Dessa forma, o discurso do historiador deveria afastar-se do fictício e aproximar-se do real. Fabricio A. A. Soares discorre sobre isso:

\begin{abstract}
A imaginação, ao longo do século XIX até meados do século $X X$, foi colocada no campo do irreal e, por decorrência das posições científicas da época, habitou ou tentou que ela habitasse apenas o campo da literatura. A "nova" ciência da história, então, passou a ser contraposta à imaginação, e seu corolário, a literatura, passou a ser tomado como representação do imaginável enquanto que a historiografia veio a ser interpretada como representação do real (SOARES, 2019, p. 25-26).
\end{abstract}

Ao demonstrar que a história enquanto ciência nasceu afastada da literatura, gostariamos de reiterar que o que nos interessa nesse momento é discutir como a literatura pode ser utilizada como fonte de pesquisa para a historiografia e que o que separa esses dois campos do saber não é que a história seja a reconstrução correta e verdadeira daquilo que aconteceu no passado, mas que trabalhamos com duas modalidades discursivas que se apropriam da realidade. Essa ruptura entre história e literatura é antiga na historiografia ocidental. Devido a sua luta contra os mitos e as lendas, a historiografia afastou-se do saber comum, e, por isso, essa discussão merece atenção.

\footnotetext{
1 Universidade de Passo Fundo (UPF), Passo Fundo, RS, Brasil.

Para compreender essa consolidação, é preciso pensar em qual contexto ela ocorreu, dessa maneira: a Alemanha da metade do século XVII até o XVIII, principalmente a região da Prússia, passou por vários conflitos internos e externos. Diante desse panorama, a cultura alemã sofreu muita interferência da cultura francesa e inglesa. A partir do século XVIII e XIX, houve um grande avanço da ciência na Europa, e, com isso, a burguesia se estabeleceu enquanto classe social. A partir desse momento, começou a surgir a necessidade de um Estado Nacional forte, ou seja, a formação de uma identidade nacional unificada. Foi nesse contexto que o historicismo nasceu, ligado diretamente a questões politicas, pois era preciso evitar os ideais revolucionários e a tomada de poder pela população, a nação precisava fundamentar suas bases.
} 
A maioria dos historiadores do século XIX não compreendiam que, quando se trata de lidar com fatos passados, a consideração básica para aquele que tenta representá-los fielmente são as noções que ele leva às suas representações das maneiras pelas quais as partes se relacionam com o todo que elas abrangem. Não compreendiam que os fatos não falam por si mesmos, mas que o historiador fala por eles, fala em nome deles, e molda os fragmentos do passado num todo cuja integridade é - na sua representação - puramente discursiva. Os romancistas podiam lidar apenas com eventos imaginários enquanto os historiadores se ocupavam dos reais, numa totalidade compreensivel capaz de servir de objeto de uma representação é um processo poético (WHITE, 2014, p. 141).

Na segunda metade do século XX, transformações teóricas tanto na filosofia da linguagem como na filosofia da ciência transformaram a escrita da história e a escrita da literatura. Devido a vários movimentos que ocorreram ao longo do século $X X$, a historiografia passou por uma renovação, exemplo disso foram os Annales na França. O oficio do historiador passou a ser ligado a questões que são formuladas no tempo presente (Marc Bloch e Lucien Febvre são exemplos), e não por meio da neutralidade e objetividade exigidas ao pesquisador para que conseguisse chegar à verdade histórica, como acontecia no século XIX. Essas questões propostas, principalmente ligadas à subjetividade, trouxeram a literatura como uma fonte de pesquisa para os historiadores.

O cuidado que se tinha no século XIX em relação a que tipo de fonte poderia ser utilizada ainda é pertinente atualmente, pois é por meio da análise de materiais que o historiador pensa o passado e produz conhecimento. Dominick LaCapra (1939) entende que a verdade buscada pelos historiadores contém implicações epistemológicas que ultrapassam a questão metodológica. Nesse sentido suas considerações contribuem para pensar além da rigidez historiográfica marcada no século XIX. "Para Dominick LaCapra, em primeiro lugar deveriamos entender o texto produzido por gerações passadas como o uso situado de uma determinada linguagem." (SILVA; SOARES, 2018, p. 33).

Não é possivel discorrer sobre o campo da teoria literária na historiografia sem citar Meta-História, livro lançado no ano de 1973 pelo historiador norte-a- mericano Hayden White (1928-2018), que foi capaz de provocar uma série de discussões entre historiadores, uma vez que defendia a ideia de que existe uma estrutura da imaginação histórica e que nossas narrativas tanto historiográficas quanto literárias referentes a acontecimentos passados estariam sujeitas a regras da inconsciência. Esse livro mudou os rumos da teoria da história e da historiografia. Nas últimas quatro décadas as ciências humanas foram marcadas por uma série de estudos entre a relação da história com a literatura que abordaram White mesmo que de formas dissonantes.

Esses debates que levam em consideração a importância da linguagem na escrita da historiografia e as relações entre a história e a literatura culminaram na escrita do livro História e literatura: abordagens interdisciplinares (objeto desta resenha) que começou a tomar forma no final do ano de 2016, com o grupo de Pesquisa: "História e Literatura: entrecruzamentos entre a história e a literatura", certificado pelo CNPq (Conselho Nacional de Desenvolvimento Científico e Tecnológico), e, ao longo do ano de 2017, as inúmeras reuniões tiveram como o centro das discussões as relações entre história e literatura. O objetivo foi buscar compreender os novos fundamentos teóricos que, em meados do século XX, transformaram a relação entre história e literatura, repensando suas escritas.

Fabrício Antônio Antunes Soares, um dos organizadores da obra exposta, possui graduação em História pela Universidade Federal de Santa Maria (2008), mestrado em História pela Universidade Federal do Rio Grande do Sul (2011) e doutorado em História na Pontificia Universidade Católica do Rio Grande do Sul (2016), com experiência na área de História, com ênfase em História da historiografia e História Cultural. Já Ricardo Oliveira da Silva, possui graduação em História pela Universidade Federal de Santa Maria (2005), mestrado em História pela Universidade Federal do Rio Grande do Sul (2008) e doutorado em História pela Universidade Federal do Rio Grande do Sul (2013), com experiência na área de História, ênfase em História das Ideias, Historiografia e teoria da História e História do Brasil do século XX. 
O livro tem como autor do primeiro capítulo Fabrício Antônio Antunes Soares, com o título: "Entre a historiografia e a literatura: a imaginação". Nesse, ele discorre sobre o conceito de imaginação ${ }^{3}$ analisado pelo filósofo francês René Descartes (1596-1650), que, em seu livro Discurso do método (1637), afirma que os nossos sentidos podem nos enganar. Para nos afastar dos enganos sensoriais, Descartes cria um princípio válido para o conhecimento: "eu penso, logo existo" (DESCARTES, 2004, p. 62), uma vez que para ele é necessário existir para poder pensar. "Em Descartes, a história e o literário estariam juntos não porque ambos fossem ou divertimento ou portadores de exemplos, mas porque ambos jamais eram conhecimento" (SOARES, 2019, p. 28). Fabrício finaliza sua exposição sobre a imaginação com o historiador norte-americano Hayden White (1928-2018), que buscou, ao longo de seu trabalho, demonstrar os potenciais poéticos e retóricos, que foram, de forma proposital, deixados de lado nos debates sobre a historiografia e que fazem parte de sua produção. Para Fabrício, o uso da imaginação na escrita da historiografia e da literatura pode ser um fator positivo capaz de fomentar essa relação. Dessa forma:

O problema não é a natureza dos tipos de eventos com que se ocupam historiadores e escritores imaginativos. O que nos deveria interessar na discussão da "literatura do fato" ou, como preferi chamar, das "ficções da representação factual", é o grau em que o discurso do historiador e o do escritor imaginativo se sobrepõem, se assemelham ou se correspondem mutuamente (WHITE, 2014, p. 137).

No capítulo II, "O livro Literatura como missão: considerações sobre história, literatura e historiografia", Ricardo Oliveira da Silva utiliza a obra do historiador Nicolau Sevcenko (1952-2014) para refletir sobre o papel da literatura na construção do conhecimento histórico. Ele começa expondo definições, embasado em diferentes autores, do que seria a história e a literatura, apresentando as características das décadas de 1970 e 1980, no Brasil, relacionadas ao contexto historiográfico. Para
Ricardo, a obra de Sevcenko permitiu o encontro de história e literatura em um momento em que as pesquisas historiográficas se voltavam, em sua maioria, para história econômica, política e social.

André Cechinel (Doutor em Literatura) em: "O império da Teoria (literária) e a literatura ausente", retrata a importância da teoria literária nas esferas da crítica, utilizando o livro Theory's Empire: an anthology of dissent, de autoria de Dephane Patai (1977). "Para Cechinel, haveria apenas operações teóricas autorreguladoras, o que demonstraria a propagação de projetos interpretativos que se conservam inalterados" (SOARES; SILVA, 2019, p. 9). Para ele, a crítica literária não tem um objeto específico de estudo, é um laboratório de (re) produção de teorias.

Em "Entre a pluma e a câmara: literatura, fotografia e história em Juan Rulfo", Carlos Alberto Sampaio Barbosa (Doutor em História Social) estabelece uma relação entre literatura, fotografia e história por meio de duas obras literárias: El llano en llamas e Pedro Paramo. Para Barbosa, não é possivel separar a fotografia, a história e a literatura, ambas possuem uma unidade poética. $\mathrm{Na}$ conclusão do capítulo, Barbosa afirma ser impossivel fragmentar Juan Rulfo entre fotógrafo, escritor ou roteirista, pois sua obra revela um olhar polissêmico através de um passado adjacente, no qual convivem distintas temporalidades.

No quinto capítulo, intitulado "'E depois se desencadeia a tormenta de merda': ficção, história e horror em Noturno do Chile, de Roberto Bolaño", Fabio da Silva Sousa (Doutor em História) aborda a ditadura chilena, implantada em 1973, por meio de uma obra de ficção que liga história e literatura. Sousa admite que a obra escolhida é complexa e densa e, por isso, abre um leque de possibilidades de interpretação. Para ele, ficção e realidade entrelaçam-se em muitos momentos. Indo além das questões teóricas relacionando história e literatura, esse capitulo traz à tona a questão do ensino e da memória sobre as ditaduras militares.

Jaisson Oliveira da Silva (Doutor em História), no penúltimo capítulo, "Ricoeur e os caminhos

3 "A imaginação é, em geral, a possibilidade de evocar ou produzir imagens, independentemente da presença do objeto a que se refere" (SOARES, 2019, p. 27). É pela ausência do objeto que a imaginação, muitas vezes, é vista como um entrave na busca pelo conhecimento. 
entre a literatura e a historiografia: metáfora, narrativa e ética", parte da premissa de que tanto a historiografia quanto a literatura são narrativas que colocam em evidência o mundo da ação, tudo isso por meio do projeto hermenêutico do filósofo francês Jean Paul Gustave Ricoeur (1913-2005). Em O entrecruzamento da história e da ficção Ricoeur acredita que "por um lado, a história se serve de alguma maneira da ficção para refigurar o tempo, e em que, por outro, a ficção se serve da história com o mesmo intuito" (RICOEUR, 1997, p. 311-312). É nessa troca de lugares, na qual a história utiliza a ficção e a ficção usa a história que o tempo humano toma forma.

No último capitulo "A indianização dos colonizadores: uma reflexão sobre o processo de contrato entre sociedades indígenas e euro-americanas a partir da narrativa ficcional de Dança com Lobos", Leandro Goya Fontella (Doutor em História Social) reflete sobre a história do contato dos povos indígenas com os euro-americanos. Sua visão vai contra a ideia dualista do passado que via os indígenas como vítimas e os euro-americanos como vilões. Ele desnaturaliza a concepção de que os povos indigenas foram incorporados pelos europeus. Fontella salienta que é necessário analisar a história dos povos indigenas no Brasil de maneira diferente do que aconteceu no período colonial e nos últimos 200 anos. As discussões não podem simplesmente ser ampliadas, pois essa generalização resulta em uma incompreensão das dinâmicas sociais. Por fim, ele ainda ressalta que olhar de forma unidirecional defendendo que os povos nativos foram assimilados pela matriz cultural europeia é trithar o caminho do abismo.

Foi a partir dos anos 1960-1970 que os processos retóricos passaram a ser objeto de reflexão na escrita da história. A teoria da história reflete sobre a relação entre o passado e a linguagem. Se partirmos da ideia de que a exposição de um acontecimento histórico pode causar dúvidas em relação a sua veracidade ou ao seu teor ficcional, é possivel também questionar se um romance literário pode dialogar com fatos e personagens reais. Ao demonstrar que a historiografia também se ocupa do ficcional, é importante lembrar que "[...] há um lugar de produção, regras de produção, uma epistemologia, um modo de lidar com testemunhas e documentos, um modo de escrever, um pacto implícito com o leitor, que diferenciam a escrita da história do romance apesar das semelhanças" (SOARES, 2016, p. 35).

Segundo o historiador alemão Johann Gustav Droysen (1808-1884), que, na metade do século XIX, enfatizava que o ponto de partida de uma pesquisa é a pergunta que se faz ao material escolhido, podemos considerar que livros tanto de história quanto de literatura são passiveis de perguntas.

Grandes obras históricas com confiabilidade científica devido ao progresso documentário adequaram a arte poética e retórica à sua maneira de ver o passado. Paul Ricoeur admite que um livro de história pode ser visto como um admirável romance, e isso não diminui a sua representância, pelo contrário, contribui para realizá-la.

\begin{abstract}
A história é quase fictícia sempre que a quase presença dos acontecimentos colocados "diante dos olhos" do leitor por uma narrativa animada suprir, por sua intuitividade e sua vivacidade, o caráter elusivo da preteridade do passado, que os paradoxos da representância ilustram. A narrativa de ficção é quase histórica na medida em que os acontecimentos irreais que ela relata são fatos passados para a voz narrativa que se dirige ao leitor; é por isso que se parecem com acontecimentos passados e que a ficção se parece com a história (RICOEUR, 1997, p. 325).
\end{abstract}

O livro História e literatura: abordagens interdisciplinares é fundamental para estudiosos das ciências humanas, em especial historiadores e literatos que veem essa aproximação de dois campos do saber como algo benéfico e capaz de promover discussões profundas relacionadas ao estudo do passado e da linguagem. Os colaboradores do livro, no desenvolvimento de cada capítulo, refletiram, a partir de aspectos teóricos e estudos de casos especificos, diferentes caminhos que são possiveis de serem trilhados na escrita da história.

\section{Referências}

DESCARTES, René. Discurso do método. São Paulo: Nova Cultural, 2004. (Coleção Os Pensadores). 
RICOEUR, Paul. O entrecruzamento da história e da ficção. In: Tempo e narrativa. São Paulo: Papirus, 1997. Tomo III.

SILVA, Ricardo Oliveira da; SOARES, Fabrício Antônio Antunes. Dominick Lacapra: documentos e epistemologia na história intelectual. Historiæ, Rio Grande, v. 9 , n. 1, p. 27-37, 2018

SOARES, Fabrício Antônio Antunes. Farrapos de estórias: romance e historiografia da Farroupilha (1841-1999). 2016. Tese (Doutorado em História) - Pontifícia Universidade Católica do Rio Grande do Sul, Porto Alegre, 2016.

WHITE, Hayden. Trópicos do Discurso, ensaios sobre a crítica da cultura. São Paulo: Editora da Universidade de São Paulo, 2014.

WHITE, Hayden. Meta-história: a imaginação histórica do século XIX. São Paulo: EDUSP, 1995.

\section{Mônica Abramchuk}

Mestranda em História pela Universidade de Passo Fundo (UPF), em Passo Fundo, RS, Brasil.

\section{Endereço para correspondência}

Mônica Abramchuk

Universidade de Passo Fundo

Av. Brasil Leste, 285

São José, 99052-900

Passo Fundo, RS, Brasil 